JURNAL CEMERLANG: Pengabdian pada Masyarakat ISSN 2654-4741

Vol. 1, No. 1, 2018, $12-25$

DOI: https://doi.org/10.31540/jpm.v1i1.157

\title{
PEMBEKALAN GENERASI MUDA MUSLIM UNTUK MENJADI WIRAUSAHA DENGAN PENDEKATAN INKUBATOR BISNIS ISLAMI DI STIE BI CIPUTAT, TANGERANG SELATAN
}

Jaharuddin, Budi Asmita

Universitas Muhammadiyah Jakarta, Indonesia

\begin{abstract}
ABSTRAK
Era distruptif ditandai dengan digitalisasi, otomatisasi, kepintaran buatan, printer tiga dimensi dan internet of thing, semua sendi kehidupan terkoneksi dengan internet, sehingga perubahan semakin cepat dan tidak diprediksi, "Ancaman datang dari lawan-lawan tak kelihatan yang semula tidak pernah kita anggap sebagai saingan”. Maka diperlukan pembekalan generasi muda muslim untuk merubah pola fikir dan tindakan baru untuk menghadapi perkembangan ini, salah satunya adalah melalui pendekatan inkubator bisnis Islami. Inkubator Bisnis Islami, menjadi wahana tempat dikembangkannya tenant pengusaha muslim yang tangguh menghadapi masa depan dengan prinsip nilai-nilai islam. Metode yang digunakan adalah pendidikan masyarakat dan konsultasi berupa bimbingan untuk menjadi wirausaha dengan Pendekatan (a). Tatap muka clasical di kelas (seperti layaknya kuliah). (b). Diskusi. (c). Penugasan. (d). Praktikum di pasar. (e). Memulai usaha. Mitra pengabdian adalah Yayasan Pemuda Mutiara Bangsa (YPMB) Ciputat, yang merupakan yayasan yang membawahi Sekolah Tinggi Ilmu Ekonomi Bisnis Indonesia (STIE BI) Ciputat, yang bekerjasama dalam menginisasi terbentuknya mindset bisnis Islami di kalangan mahasiswa terpilih sebanyak 23 orang. Pengabdian masyarakat ini menghasilkan upaya peningkatan pengetahuan dan kesadaran generasi muda muslim, pentingnya menjadi pengusaha sejak dini dengan prinsipprinsip Islam, yang dijanjikan Allah menghasilkan kesuksesan dunia dan akhirat. Kewirausahaan islam dengan sendirinya menjaga diri pengusahanya agar selalu menghidupkan nilai-nilai keislaman, bukan hanya pada tataran diri, juga keluarga, masyarakat, Negara bahkan dunia (muamalah). Semakin banyak pemuda-pemuda muslim yang menjadi pengusaha maka akan semakin memperkuat dan memajukan perekonomian Islam.
\end{abstract}

\section{KEYWORDS}

Kewirausahaan, Inkubator Bisnis, Inkubator Bisnis Islami
ARTICLE HISTORY

Received 22 November 2018

Revised 1 December 2018

Accepted 5 December 2018

CORRESPONDENCE Jaharuddin J. @ jaharuddin@umj.ac.id 


\section{JURNAL CEMERLANG: Pengabdian pada Masyarakat}

ISSN 2654-4741

Vol. 1, No. 1, 2018, $12-25$

DOI: https://doi.org/10.31540/jpm.vli1.157

\section{PENDAHULUAN}

Era distruptif ditandai dengan internet of thing, semua sendi kehidupan terkoneksi dengan internet, sehingga perubahan semakin cepat dan tidak diprediksi, "Ancaman datang dari lawan-lawan tak kelihatan yang semula tidak pernah kita anggap sebagai saingan" (Kasali, 2017). Untuk itu perlu mempersiapkan diri, masuk ke dalam sebuah lingkungan baru yang berubah dengan cepat. Tidak cukup hanya mendatangkan teknologi baru, tetapi juga perlu mempersiapkan sumber daya manusia dan kemampuan pembiayaannya. Ini adalah sebuah kesempatan besar yang tak pernah datang sebelumnya (Tumiyana, dalam Kasali, 2017).

Kondisi ini menyebabkan pelaku pasar wait and see, apa yang terjadi selanjutnya pada dunia usaha, gamang memprediksi masa depan, apakah industri yang hari ini kokoh masih bertahan dimasa depan?,Volatility, Uncertaint, Complexity, Ambiguity (VUCA) menjadi corak kehidupan belakangan ini (Brown, 2017). Perbankan dan dunia keuangan dihantui dengan berkembang pesatnya financial technology yang terus berkembang mengantikan fungsi perbankan dan lembaga keuangan.

Pelakunya adalah generasi milenial dan generasi $Z$ yang kreativitasnya tak bisa dibendung dengan berbagai inovasi yang tidak terfikirkan sebelumnya, inilah yang didefinisikan sebagai distruptif. Tidak selamanya bercorak negatif, karena saat yang sama era ini adalah peluang lahirnya inovasi baru oleh generasi baru.

Pada kondisi inilah Islamic entrepreneurship menjadi relevan digagas ulang, karena pemikiran kewirausahaan harus didasari oleh norma yang pasti kebenarannya, kewirausahaan yang didasarkan mindset kreatif, bersungguhsungguh, siap dengan berbagai tantangan, bekerjasama, dan mengunakan teknologi serta didasarkan etika adalah menjadi relatif kebenarannya, jika tidak disandarkan dengan agama. Malah kewirausahaan seperti ini bisa menghadirkan kerusakan (distruptif) pada berbagai sendi kehidupan.

Gagasan Inkubator Bisnis Islami, menjadi wahana tempat dikembangkannya tenant pengusaha muslim yang tangguh menghadapi masa depan dengan standar 


\section{JURNAL CEMERLANG: Pengabdian pada Masyarakat}

ISSN 2654-4741

Vol. 1, No. 1, 2018, $12-25$

DOI: https://doi.org/10.31540/jpm.v1i1.157

kebenaran mutlak, karena agama yang menjadi basis inspirasi dan etika agama mewarnai setiap langkah pengusaha muslim, dengan demikian kreatifitas dan inovasi yang dihadirkan adalah inovasi yang tidak melahirkan kemudharatan (kerusakan/distruptif), karena agama dihadirkan Allah Swt kemuka bumi untuk keberkahan bukan sebaliknya.

Inkubator bisnis telah lama dikembangkan dibeberapa negara maju, bahkan upaya pendirian inkubator telah dimulai sejak tahun 1959. Tenant pertama yang dibina dalam inkubator adalah usaha pengecatan papan petunjuk di New York dengan luas ruangan 1.919,6 meter persegi. Di Amerika Serikat inkubator telah berkembang sejak awal tahun 1980-an. Perkembangan inkubator lebih lanjut terjadi di negara berkembang pada pertengahan tahun 1990-an, antara lain di India, China, Malaysia, Singapura, Pilipina dan lainnya, hingga mencapai 4.000. Sementra itu suatu studi (Harley, 2001, Bank Indonesia, 2006) melaporkan bahwa jumlah inkubator pada tahun 2000 sebanyak 3.450. Perbedaan jumlah tersebut karena adanya penggolongan antara inkubator yang didirikan pemerintah (universitas) dengan inkubator yang didirikan oleh swasta yang berorientasi laba.

Tabel 1

Jumlah Inkubator Bisnis dibeberapa Negara

\begin{tabular}{|l|c|}
\hline \multicolumn{1}{|c|}{ Negara } & Jumlah Inkubator Bisnis \\
\hline Amerika Utara & 1.000 \\
\hline Amerika Selatan & 200 \\
\hline Eropa Barat & 900 \\
\hline Eropa Timur & 200 \\
\hline Timur Jauh & 1.000 \\
\hline Afrika dan Timur Tenggah & 200 \\
\hline
\end{tabular}

Sumber: Laurence, 2006, dalam BI 2006

\section{Inkubator di Indonesia}

Inkubator di Indonesia diatur dalam Perpres Nomor 27 Tahun 2013 Tujuannya adalah Value added pengelolaan potensi ekonomi melalui IPTEKs (Technology Business Incubation/TBI). Kegiatannya berbentuk Proses Pembinaan, Pendampingan, dan Pengembangan yang diberikan oleh Inkubator Wirausaha kepada Peserta Inkubasi. Peserta adalah wirausaha pemula (0-3 tahun) 


\section{JURNAL CEMERLANG: Pengabdian pada Masyarakat}

ISSN 2654-4741

Vol. 1, No. 1, 2018, $12-25$

DOI: https://doi.org/10.31540/jpm.v1i1.157

berbasis teknologi yang menjalani proses inkubasi (Tenant, klien inkubator, inkubati). Inkubator Bisnis adalah Suatu lembaga intermediasi yang melakukan proses inkubasi terhadap tenant.

Inkubator bisnis diyakini menjadi cara efektif melahirkan wirausaha baru, namun jumlah inkubator bisnis di Indonesia masih sedikit, terlihat dalam tabel berikut.

Tabel 2

Pendiri Inkubator

\begin{tabular}{|l|l|c|c|}
\hline No & \multicolumn{1}{|c|}{ Pendiri } & Jumlah & \% \\
\hline 1 & PT Negeri & 35 & 43 \\
\hline 2 & PT Swasta & 24 & 29 \\
\hline 3 & Swasta dan Perbankan & 12 & 15 \\
\hline 4 & Pemerintah & 7 & 9 \\
\hline 5 & Public Company & 3 & 4 \\
\hline \multicolumn{2}{|c|}{ Jumlah } & $\mathbf{8 1}$ & \\
\hline
\end{tabular}

Sumber: Kemenko bidang ekonomi tahun 2015

Indonesia yang membentang dari Sabang sampai Merauke, dengan penduduk 250 juta jiwa lebih, hanya mempunyai 81 inkubator, sangat memprihatinkan. Dibutuhkan keseriusan dan inisiatif banyak pihak agar inkubator bermunculan dari berbagai kalangan.

Saat ini kalangan muda terbesar adalah generasi millennial dan generasi $\mathrm{Z}$ yang sangat berpotensi untuk menjadi entrepreneur. Karakteristik generasi $\mathrm{Z}$ tergambarkan dengan 3C (Creative, Connected and Collaboration), semakin nyata dirasakan generasi milenials yang tak tahan bertahun-tahun hanya menjadi pekerja saja, mereka adalah generasi kreatif yang menginginkan kebebasan dalam banyak hal, termasuk pekerjaan. Ini momentum yang sangat berharga jika didesain dengan baik. Momentum ini harusnya diiringi dengan menjamurnya inkubator, yang menangkap peluang tersebut menjadi nyata. Dibutuhkan banyak model pengembangan kewirausahaan dalam mengoptimalkan potensi yang ada. 
JURNAL CEMERLANG: Pengabdian pada Masyarakat ISSN 2654-4741

Vol. 1, No. 1, 2018, $12-25$

DOI: https://doi.org/10.31540/jpm.vli1.157

\section{Model Pengembangan Kewirausahaan}

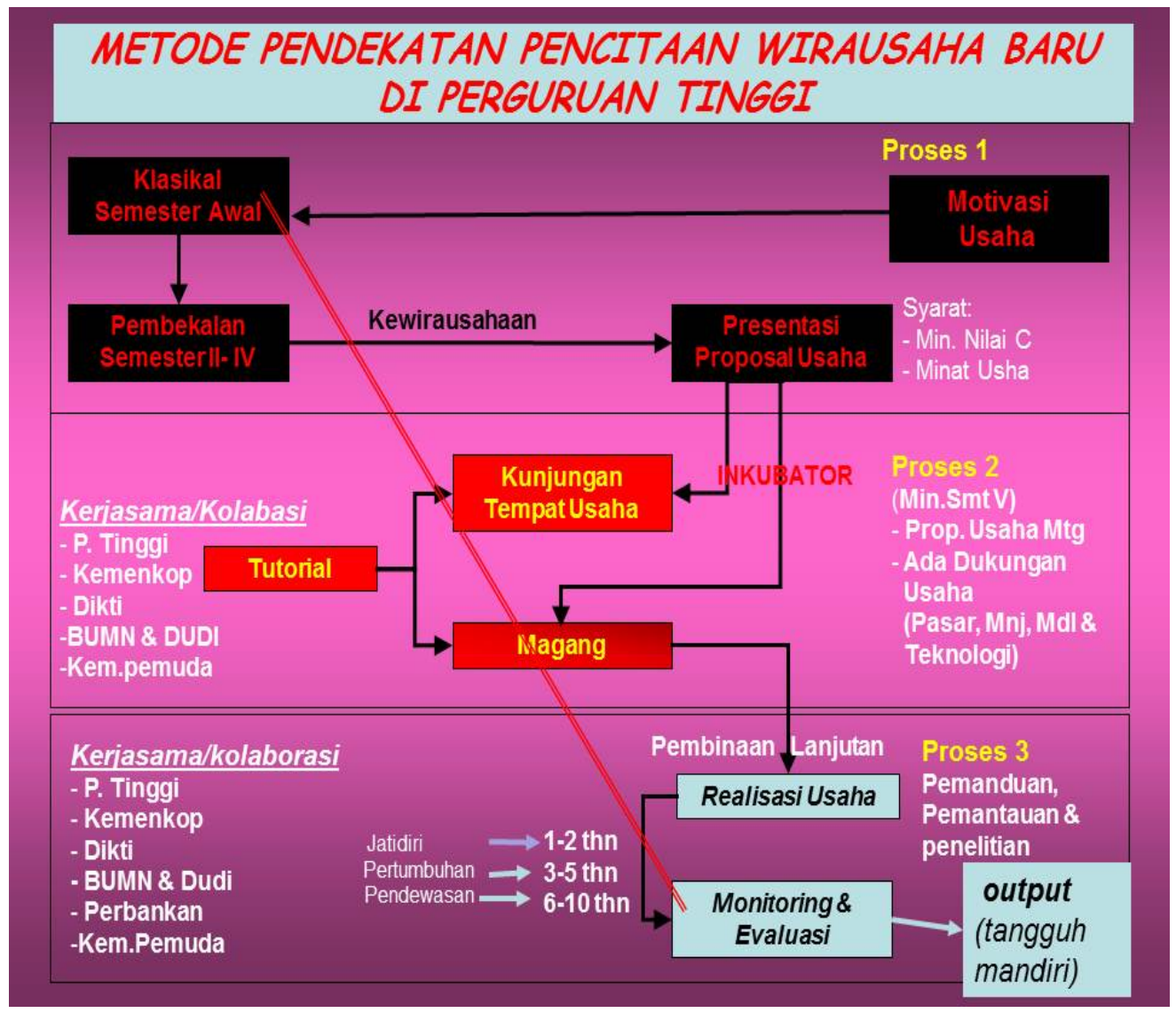

Gambar 1. Metode Pendekatan Penciptaan Wirausaha baru di Perguruan Tinggi (Mudjiarto, 2017)

Dari skema di atas, menjelaskan bahwa melaksanakan aktivitas inkubator dikalangan mahasiswa S1 mempunyai tiga tahapan utama, mulai dari motivasi usaha, sampai nanti realisasi usaha, monitoring dan outpunya wirausaha yang tangguh dan mandiri. 
JURNAL CEMERLANG: Pengabdian pada Masyarakat ISSN 2654-4741

Vol. 1, No. 1, 2018, $12-25$

DOI: https://doi.org/10.31540/jpm.v1i1.157

\section{Roadmap Pengembangan Inkubator bisnis di Indonesia}

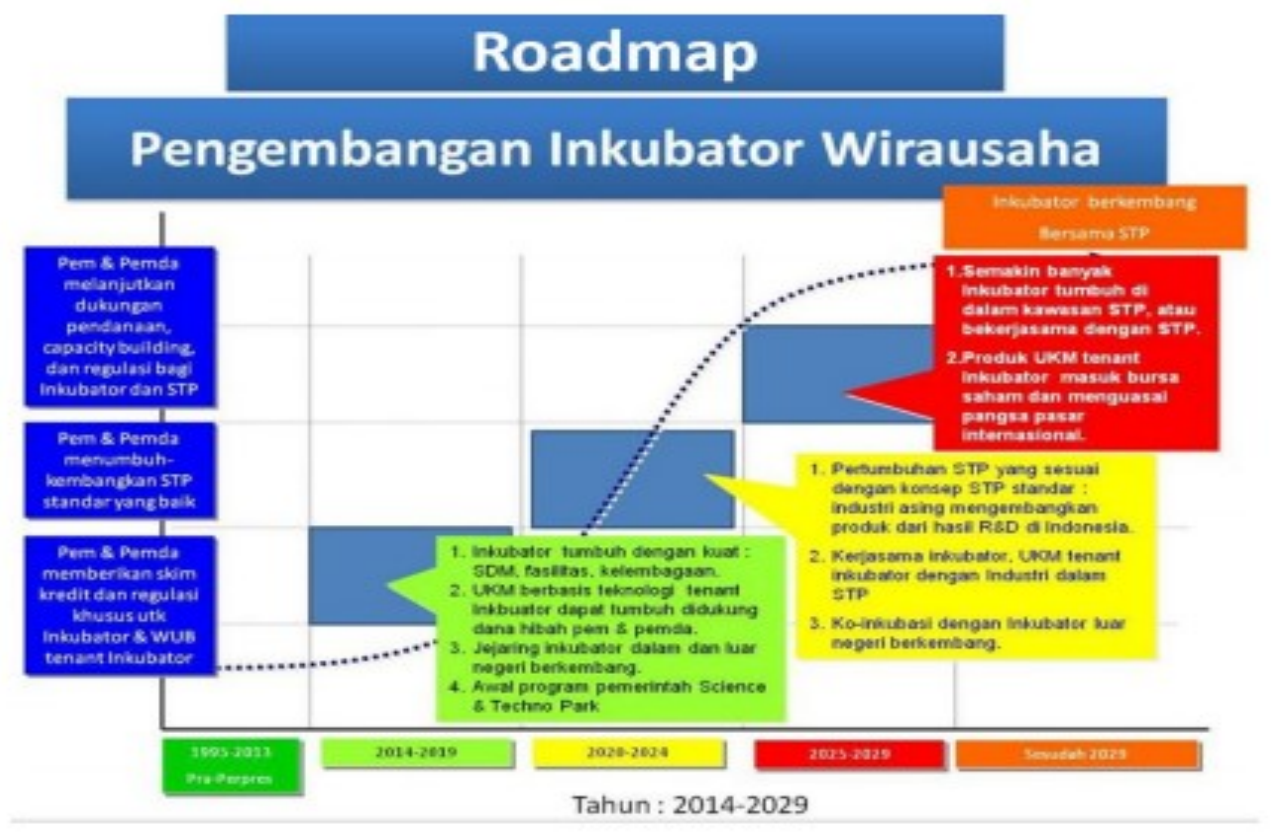

Gambar 2. Roadmap Pengembangan Inkubator Wirausaha

Menurut hasil penelitian Laurence Hewick dari Canadian Business Incubator (2006), bahwa pendirian inkubator secara umum bertujuan untuk:

1. Menciptakan lapangan pekerjaan baru;

2. Mengurangi kegagalan usaha kecil dari $89 \%$ menjadi $20 \%$

3. Pembinaan pemuda dalam suatu komunitas

4. Menfasilitasi komersialisasi dan eksport;

5. Menfasilitasi kewirausahaan dalam masa transisi ekonomi;

6. Menarik minat lulusan luar negeri untuk mengaplikasikan ilmunya

\section{MASALAH}

Kenyataanya masih banyak kalangan generasi muda terdidik yang siap menjadi karyawan setelah tamat kuliah, mata kuliah kewirausahaan masih banyak berupa teori, yang perlu didukung dengan langkah-langkah nyata agar generasi muda terbuka pemikirannya selain menjadi karyawan ada pilihan lain yaitu menjadi wirausaha. Kegiatan ini adalah langkah nyata untuk membimbing 


\section{JURNAL CEMERLANG: Pengabdian pada Masyarakat}

ISSN 2654-4741

Vol. 1, No. 1, 2018, $12-25$

DOI: https://doi.org/10.31540/jpm.v1i1.157

mahasiswa menjadi seorang wirausaha, tidak hanya berupa penyampaian materi, juga berupa praktek wirausaha. Kegiatan ini diharapkan bagian solusi melahirkan generasi muda yang siap menjadi wirausaha.

\section{METODE}

Metode yang digunakan dalam pelaksanaan pengabdian masyarakat ini adalah Pendidikan masyarakat berupa pelatihan yang bertujuan untuk meningkatkan pemahaman generasi muda dalam meningkatkan pemahaman serta kesadaran pentingnya menjadi wirausaha. Juga digunakan metode Konsultasi berupa pendampingan peserta untuk praktek dan memulai usaha. Pengabdian masyarakat ini diadakan dari Februari - Juni 2017 bertempat di kampus STIE Bisnis Indonesia Kampus Ciputat, dan juga di pasar kebayoran Lama, Jakarta Selatan. Dengan mahasiswa sebanyak 23 orang. Sedangkan narasumber adalah tim FEB UMJ seperti Jaharuddin dan Budi Asmita.

Pendekatan yang digunakan adalah: (a) Tatap muka clasical di kelas (seperti layaknya kuliah). (b) Diskusi. (c) Penugasan. (d) Praktikum di pasar. (e) Memulai usaha

\section{PEMBAHASAN}

Pada pembahasan akan diuraikan satu persatu urutan pelaksanaan program ini mulai dari persiapan, pelaksanaan, teknis pelaksanaan, praktikum, hasil dan pra pelaksanaan yang diuraikan berikut ini:

\section{Persiapan}

Pada tahap ini dosen FEB UMJ menyiapkan modul ajar, untuk memudahkan peserta dalam mengikuti program dan Alhamdulillah modul telah ada, dalam bentuk power point yang menarik, dengan tema: (1). Tauhid dan Maqashid Syariah, sebagai fondasi bisnis Islami. (2). Quwwatul Mall. (3). Dagang dalam Al Qur'an. (4). Islamic Entrpreneurship. (5). 14 langkah rasulullah dalam membangun kerajaan bisnis. (6). Rahasia Bisnis Rasulullah. (7). Cerdas Bisnis cara Rasulullah. (8). Strategi mendapatkan pembiayaan Bank Syariah. (9). 


\section{JURNAL CEMERLANG: Pengabdian pada Masyarakat}

ISSN 2654-4741

Vol. 1, No. 1, 2018, 12 - 25

DOI: https://doi.org/10.31540/jpm.v1i1.157

Manajemen Keuangan UKM. (10). Menjadi Pribadi kreatif.

Kemudian tim juga menyiapkan panduan praktikum yang kami beri tema:Mendobrak mitos susah jadi wirausaha“ide, negosiasi, eksekusi usaha itu mudah", yang kami siapkan untuk 180 menit praktikum.

Setelah semua persiapan, langkah selanjutnya adalah menghubungi pihak Yayasan Pemuda Mutiara Bangsa (YPMB), membahas kesediaan untuk menjadi mitra dalam mengadakan Inkubator Bisnis Islam, dan Alhamdulillah, Bapak Farid Wajdi, S.E, M.Si sebagai ketua Yayasan Pemuda Mutiara Bangsa (YPMB) menyambut positif pelaksanaan Inkubatior Bisnis ini, dan memberikan surat dukungan tertulis.

\section{Pelaksanaan}

\section{Penyampaian Materi dalam bentuk clasical}

Kegiatan berlangsung setiap pekan, pukul 8 - 9.45 setiap pekan dari bulan Februari 2017 sampai dengan Juni 2017, diselingi praktikum di pasar dan memulai usaha, seperti terlihat dalam tabel berikut ini:

Tabel 3.

Jadwal kegiatan

\begin{tabular}{|c|c|c|c|c|}
\hline No & Tanggal & Bentuk Kegiatan & Tema yang disampaikan & Ket \\
\hline 1 & $\begin{array}{ll}28 & \text { Februari } \\
2017 & \end{array}$ & $\begin{array}{l}\text { Penyampaian } \\
\text { materi dalam } \\
\text { bentuk clasical }\end{array}$ & $\begin{array}{l}\text { Tauhid dan maqashid } \\
\text { syariah sebagai fondasi } \\
\text { bisnis islami }\end{array}$ & \\
\hline 2 & 7 Maret 2017 & $\begin{array}{l}\text { Penyampaian } \\
\text { materi dalam } \\
\text { bentuk clasical }\end{array}$ & Quwwatul Maal & \\
\hline 3 & 13 Maret 2017 & $\begin{array}{l}\text { Penyampaian } \\
\text { materi dalam } \\
\text { bentuk clasical }\end{array}$ & Dagang dalam Al Qur'an & \\
\hline 4 & 21 Maret 2017 & $\begin{array}{l}\text { Praktikum ke } \\
\text { Pasar Kebayoran } \\
\text { Lama }\end{array}$ & $\begin{array}{l}\text { Mendobrak mitos susah } \\
\text { jadi wirausaha } \\
\text { "ide, negosiasi, eksekusi } \\
\text { usaha itu mudah" }\end{array}$ & $\begin{array}{l}180 \\
\text { menit }\end{array}$ \\
\hline 5 & 4 April 2017 & $\begin{array}{l}\text { Penyampaian } \\
\text { materi dalam } \\
\text { bentuk clasical }\end{array}$ & Islamic Entrpreneurship & \\
\hline 5 & 11 April 2017 & $\begin{array}{l}\text { Penyampaian } \\
\text { materi dalam } \\
\text { bentuk clasical }\end{array}$ & $\begin{array}{l}14 \text { langkah rasulullah } \\
\text { dalam membangun } \\
\text { kerajaan bisnis }\end{array}$ & \\
\hline
\end{tabular}

https://ojs.stkippgri-lubuklinggau.ac.id/index.php/JPM 
JURNAL CEMERLANG: Pengabdian pada Masyarakat ISSN 2654-4741

Vol. 1, No. 1, 2018, 12 - 25

DOI: https://doi.org/10.31540/jpm.v1i1.157

\begin{tabular}{|c|c|c|c|}
\hline 6 & 18 Maret 2017 & $\begin{array}{l}\text { Penyampaian } \\
\text { materi dalam } \\
\text { bentuk clasical }\end{array}$ & Rahasia Bisnis Rasulullah \\
\hline 7 & 23 Mei 2017 & $\begin{array}{l}\text { Penyampaian } \\
\text { materi dalam } \\
\text { bentuk clasical }\end{array}$ & $\begin{array}{lll}\text { Cerdas } & \text { Bisnis } & \text { cara } \\
\text { Rasulullah } & & \end{array}$ \\
\hline 8 & 26 Mei 2017 & $\begin{array}{l}\text { Penyampaian } \\
\text { materi dalam } \\
\text { bentuk clasical }\end{array}$ & $\begin{array}{l}\text { Strategi mendapatkan } \\
\text { pembiayaan Bank Syariah }\end{array}$ \\
\hline 9 & 29 Mei 2017 & $\begin{array}{l}\text { Penyampaian } \\
\text { materi dalam } \\
\text { bentuk clasical }\end{array}$ & $\begin{array}{l}\text { Manajemen Keuangan } \\
\text { UKM }\end{array}$ \\
\hline \multirow[t]{2}{*}{10} & \multirow[t]{2}{*}{1 Juni 2017} & $\begin{array}{l}\text { Penyampaian } \\
\text { materi dalam } \\
\text { bentuk clasical }\end{array}$ & Menjadi Pribadi kreatif \\
\hline & & Penutupan & \\
\hline
\end{tabular}

\section{Praktikum}

Ketika Rasulullah SAW beserta para sahabat hijrah dari Makkah ke Madinnah, Rasulullah dan para sahabat meninggalkan semua harta kekayaannya di Makkah.Mereka memulai kehidupan baru di Madinah.Kaum Anshar yang ada di Madinah, menawarkan berbagai fasilitas kepada saudaranya yang baru datang dari Makkah (Kaum Muhajirin), termasuk mengelola harta kekayaan kaum Anshar di Madinah.

Dalam rombongan yang hijrah dari Makkah ke Madinah tersebut, ada Abdurahman bin Auf yang dikenal sebagai konglomerat di Makkah. Abdurahman bin Auf ketika mendapat tawaran fasilitas dari saudara barunya dari kaum Anshar, dia tidak langsung menerimanya. Yang diminta adalah meminta kepada kaum Anshar untuk menunjukkan pasar, dari pasar inilah Abdurahman bin Auf kembali memulai usahanya, dan dari proses inilah, akhirnya Abdurahman bin Auf kembali menjadi konglomerat di kota Madinah.Dari kisah bersejarah ini, kita bisa menarik pelajaran berharga bahwa, modal utama setiap orang dalam berusaha adalah apa yang ada didirinya, yang lain adalah faktor pendukung. Terinspirasi dari kisah ini, maka dibuatlah praktikum ini, dengan harapan banyak pelajaran dan pengalaman yang bisa dirasakan oleh mahasiswa. 


\section{JURNAL CEMERLANG: Pengabdian pada Masyarakat}

ISSN 2654-4741

Vol. 1, No. 1, 2018, $12-25$

DOI: https://doi.org/10.31540/jpm.v1i1.157

\section{Teknis Pelaksanaan}

1. Mahasiswa kumpul di halaman depan kampus, diberikan pengarahan terlebih dahulu

2. Mahasiswa menyisakan uang Rp. 5.000,- untuk biaya transportasi angkutan kota ke tempat praktikum (pasar Kebayoran Lama)

3. Mahasiswa mengumpulkan handphone (alat komunikasi) dan uang, dan disimpan di tempat yang aman, dipastikan mahasiswa tidak menyimpan uang di tubuhnya.

4. Mahasiswa memasang identitas diri yang telah disiapkan, sebagai tanda ikut praktikum, dan memudahkan identifikasi saat di lapangan oleh tim pemantau.

5. Mahasiswa mengisi lembar Presensi terlebih dahulu, dan di cek oleh dosen pembimbing

6. Mahasiswa berangkat berkelompok (masing-masing 2 orang), di angkutan kota yang berbeda menuju lokasi praktek

7. Sampai di lokasi praktek mahasiswa langsung "aksi”, mencari produk/jasa, dan menjualnya, hingga ada hasil.

8. Paling lambat pukul $13.00 \mathrm{WIB}$, bagi yang pagi dan pukul $16.00 \mathrm{WIB}$ bagi yang sore, berkumpul di meeting point (masjid di depan stasiun kereta api Kebayoran Lama) untuk mendapat pengarahan dan evaluasi

9. Mahasiswa diabsen kembali saat dikumpulkan di Meeting point.

10. Mahasiswa diingatkan untuk membuat kisah penjualannya, untuk laporan praktikum.

11. Bersama-sama pulang dan selesai. 
JURNAL CEMERLANG: Pengabdian pada Masyarakat ISSN 2654-4741

Vol. 1, No. 1, 2018, $12-25$

DOI: https://doi.org/10.31540/jpm.vli1.157

Berikut beberapa dokumentasi kegiatan.

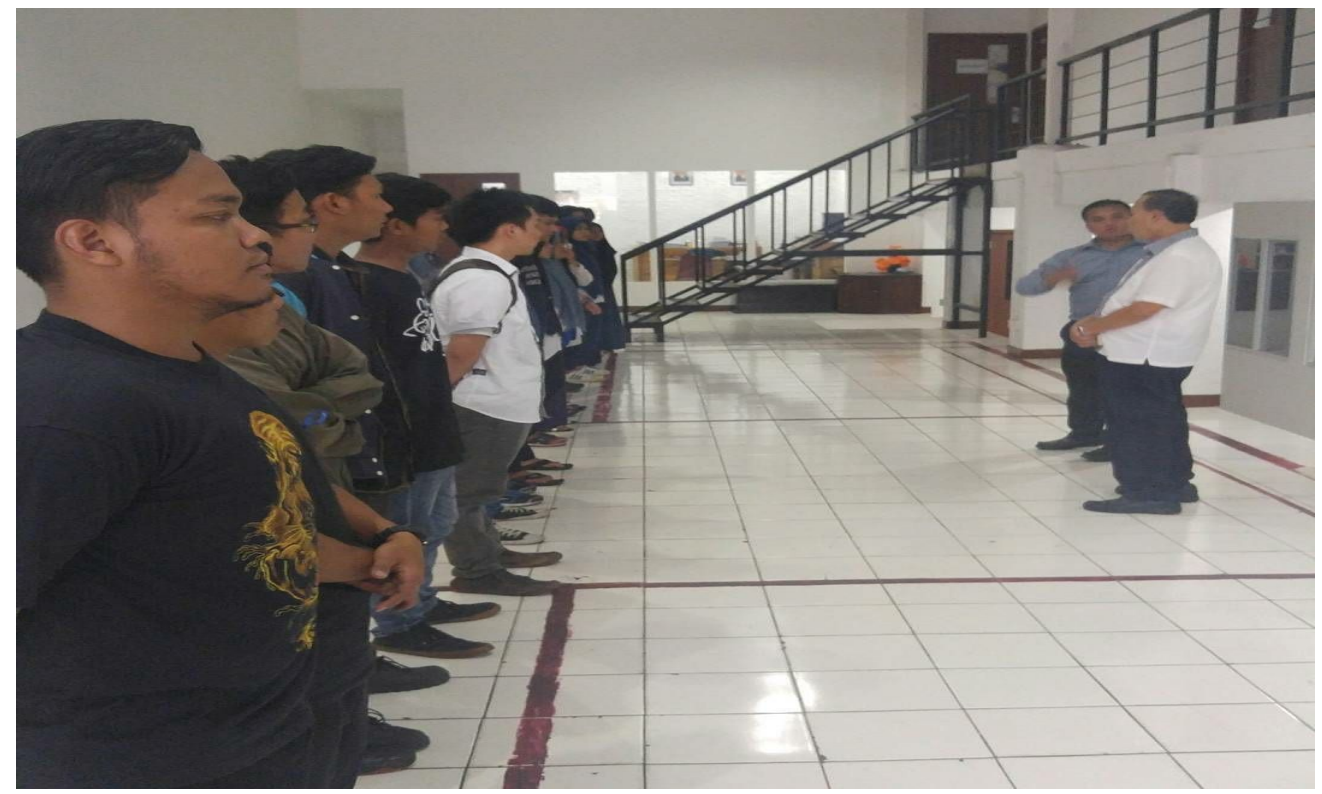

Gambar 3. Persiapan sebelum tenant praktikum di Pasar.

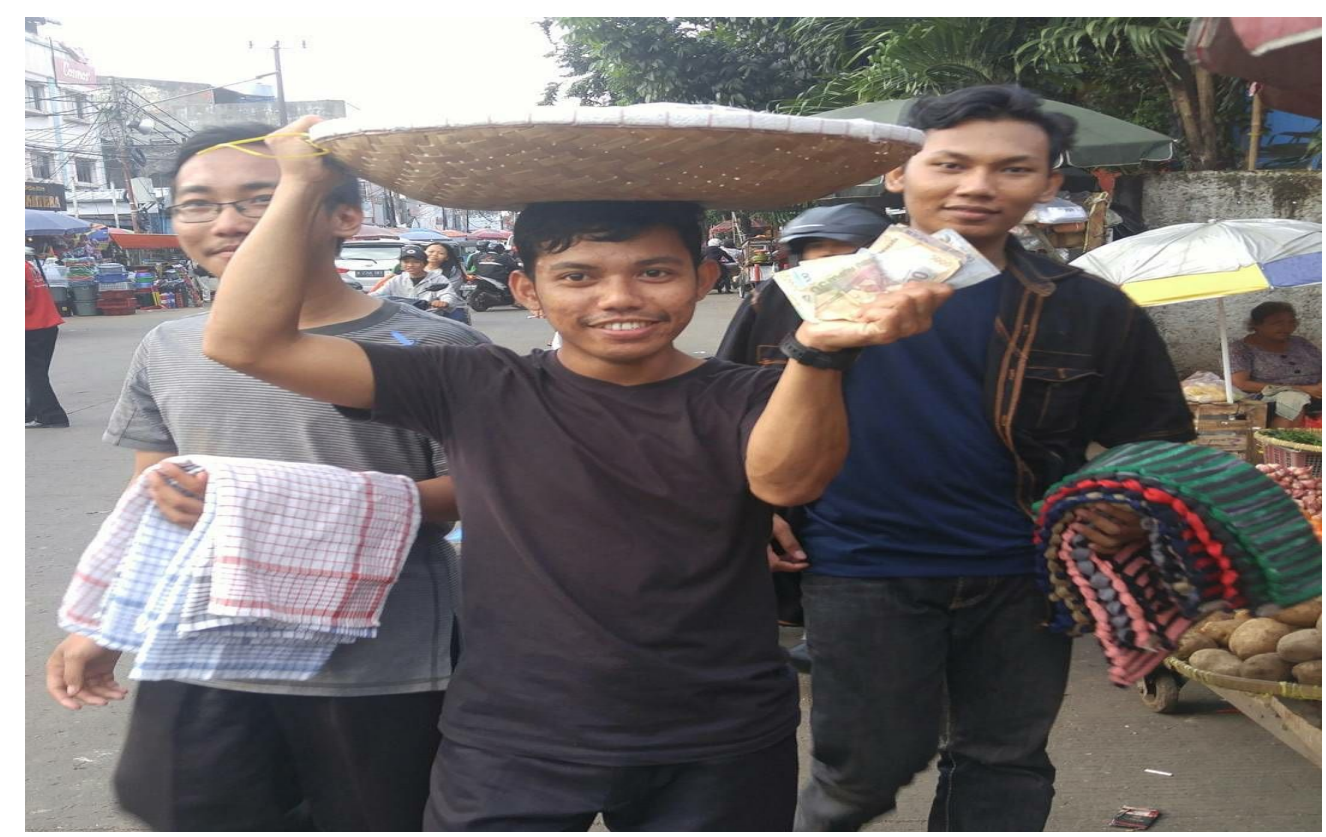

Gambar 4. Tenant sedang praktikum dipasar

https://ojs.stkippgri-lubuklinggau.ac.id/index.php/JPM 
JURNAL CEMERLANG: Pengabdian pada Masyarakat ISSN 2654-4741

Vol. 1, No. 1, 2018, $12-25$

DOI: https://doi.org/10.31540/jpm.vli1.157

Produk dan jasa yang dijual oleh peserta adalah produk dan jasa yang spontanitas mereka cari dan dapatkan dipasar, mereka tidak diperbolehkan mempunyai produk sebelumnya.

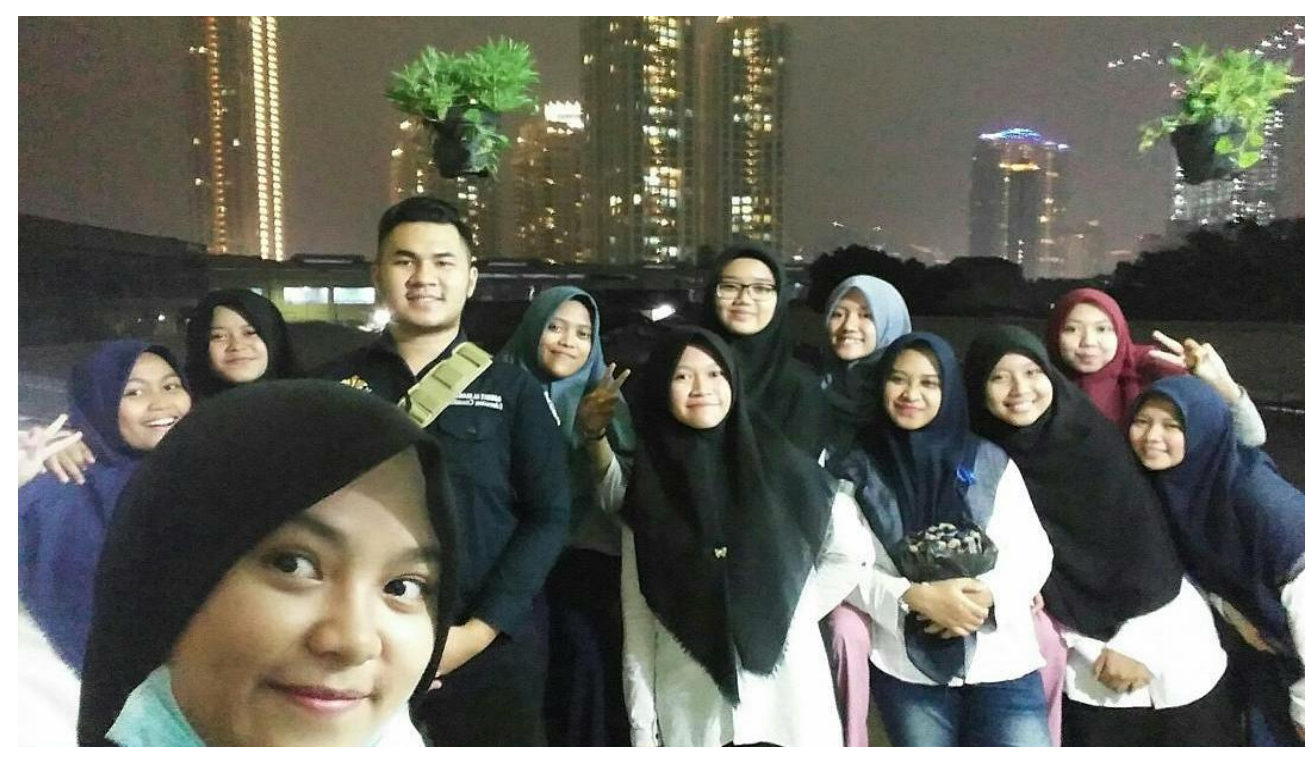

Gambar 5. Suasana kegembiraan setelah evaluasi akhir di Pasar

\section{HASIL}

Dari hasil test akhir peserta berupa test tertulis dan diskusi, terlihat dengan jelas, kegiatan ini memberi dampak kepada peserta, dan sebagian peserta ingin bersungguh-sungguh untuk menguatkan tekad, untuk memulai usaha, sesuai dengan minat masing-masing, disamping itu kegiatan ini juga memberi bekal yang kaut kepada peserta bahwa islam memberi inspirasi untuk umatnya menjadi wirausaha. Tanggan diatas lebih utama daripada tanggan dibawah, menjadi pengusaha lebih utama daripada menjadi karyawan, ibadah lebih mudah dan nyaman jika menjadi seorang wirausaha.

\section{Paska Pelaksanaan}

Setelah pelaksanaan program, dibutuhkan pendampingan selanjutnya, agar mindset yang terbentuk, untuk menjadi pengusaha muda yang Islami, bisa dipertahankan, bukan hanya menjadi pengusaha yang tangguh, tapi saat yang sama menjadi pengusaha yang senantiasa menjalankan perintah Allah SWT dan https://ojs.stkippgri-lubuklinggau.ac.id/index.php/JPM 
JURNAL CEMERLANG: Pengabdian pada Masyarakat ISSN 2654-4741

Vol. 1, No. 1, 2018, $12-25$

DOI: https://doi.org/10.31540/jpm.v1i1.157

menjauhi laranganNYA baik dalam beribadah maupun bermuamalah.

\section{KESIMPULAN DAN SARAN}

Dari pembahasan di atas, dapat ditarik beberapa kesimpulan sebagai berikut:

1. Inkubator Bisnis Islami, merupakan wadah ditumbuh kembangkannya jiwa kewirausahaan islam dalam diri para pengusaha muslim

2. Corak Kewirausahaan islam adalah menyadari bahwa islam menganjurkan umatnya untuk menjadi pengusaha, karena aktivitas keislaman akan optimal jika umatnya mempunyai kekayaan yang banyak, banyak aktivitas keislaman yang bisa dikerjakan dengan optimal jika mempunyai kekayaan yang maksimal.

3. Tidak hanya menyadari, kewirausahaan islam dengan sendirinya menjaga diri pengusahanya agar selalu menghidupkan nilai-nilai ke islaman, bukan hanya pada tataran diri, juga keluarga, masyarakat, Negara bahkan dunia (muamalah).

4. Semakin banyak pemuda-pemuda muslim yang menjadi pengusaha maka akan semakin memperkuat dan memajukan perekonomian Islam.

5. Beberapa saran adalah sebagai berikut: (1).Proses pembentukan pengusaha muslim melalui incubator bisnis islami, tidak cukup hanya dijalankan dalam hitungan bulan, inkubator bisnis islami adalah program bekelanjutan yang terus menjaga pengusaha muslim berkembang sampai tangguh. (2). Untuk itu perlu dilembagakan, dalam program berkelanjutan, sehingga semakin banyak yang mendapatkan manfaat dan semakin banyak pengusaha yang terjaga nilai-nilai keislamannya, dan baik untuk bangsa Indonesia. 
JURNAL CEMERLANG: Pengabdian pada Masyarakat ISSN 2654-4741

Vol. 1, No. 1, 2018, $12-25$

DOI: https://doi.org/10.31540/jpm.v1i1.157

\section{UCAPAN TERIMA KASIH}

Terima kasih kami ucapkan kepada Bapak Dr. Andry Priharta, S.E,.M.M. Dekan FEB UMJ dan seluruh pimpinan Fakultas Ekonomi dan Bisnis Universitas Muhammadiyah Jakarta, yang telah memberikan kesempatan, mendanai dan mensupport penuh terlaksananya pengabdian masyarakat ini.

\section{DAFTAR PUSTAKA}

Brown, P. T. (2017). Slide presentasi Seminar Bank Indonesia, dengan tema "Transformational Leadership, coping with the callenge in the VUCA environment". Yogyakarta, 18 Oktober 2017.

Bank Indonesia. (2006), Kajian Inkubator Bisnis dalam rangka pengembangan UMKM, Tim Penelitian dan pengembangan Biro Kredit

Kasali. (2017). Tomorrow is today, inilah Inovasi distruptif perusahaan Indonesia dalam menghadapi lawan-lawan tak kelihatan, Rumah Perubahan dan Mizan. Bandung.

Kemenko bidang Ekonomi tahun 2015

Kementiran Koordinator Bidang Ekonomi Republik Indonesia, tahun 2015

Mudjiarto. (2017). Slide presentasi workshop pembentukan Pusat Inkubator dan Kewirausahaan (PIBK) UMJ.

Peraturan Presiden Republik Indonesia Nomor 27 Tahun 2013 tentang Pengembangan Inkubator Wirausaha 